\title{
Diagnóstico de Sífilis a Partir de Lesões da Mucosa Oral
}

\author{
Syphilis Diagnosis Made from Oral Mucosal Lesions
}

Luis UVA ${ }^{1}$, João BORGES-COSTA ${ }^{1,2}$, Paulo FILIPE ${ }^{1,2}$

Acta Med Port 2014 May-Jun;27(3):403-403

Palavras-chave: Doenças da Boca; Sífilis; Sífilis Cutânea; Treponema pallidum.

Keywords: Mouth Diseases; Syphilis; Syphilis, Cutaneous; Treponema pallidum.

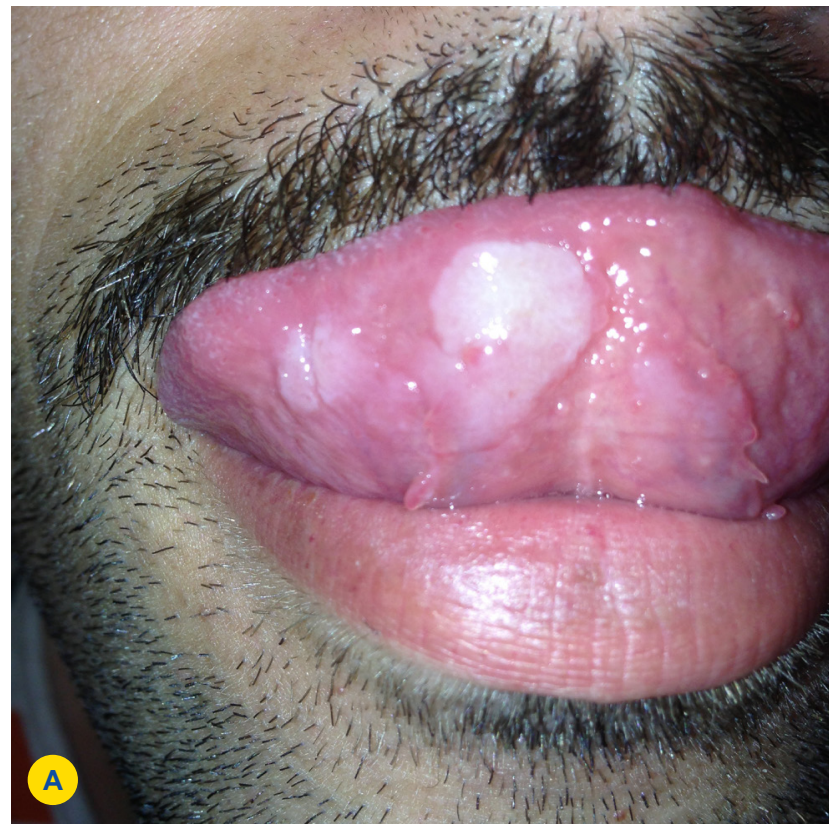

Figura 1A - Condilomas planos da mucosa oral

Descreve-se o caso de um homem de 28 anos, com placa esbranquiçada na face inferior da língua com uma semana de evolução (Fig.1a). Referia também aparecimento de placa com descamação no dorso do pénis 6 semanas antes. Analiticamente tinha TPHA positivo (1/32), VDRL reativo (32 diluições), presença de anticorpos no soro para Treponema pallidum e serologia VIH $1 / 2$ negativa.

As lesões de sífilis secundária podem ter variadas formas clínicas, aparecem 6 a 8 semanas após o complexo primário e os condilomas planos são as que têm maior po-

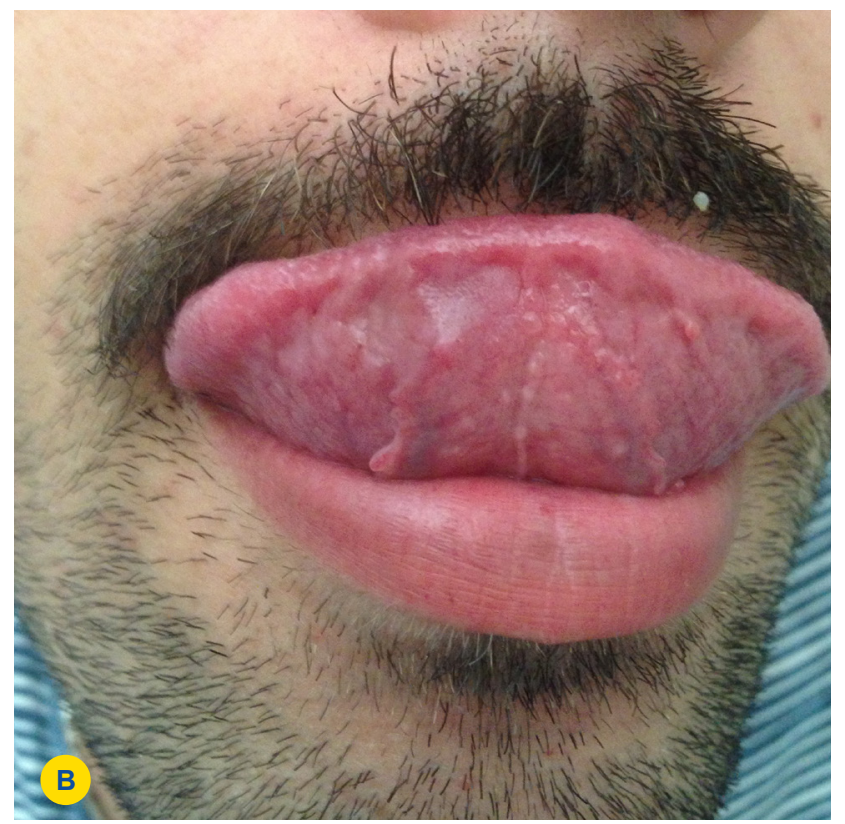

Figura 1B - Uma semana após tratamento

tencial de contágio. ${ }^{1}$

Foi administrada benzilpenicilina benzatínica por via intramuscular em dose única de 2.4 M.U.I Verificou-se reação de Jarisch-Herxheimer 10 horas após terapêutica e desaparecimento das lesões em poucos dias (Fig. 1b). ${ }^{2}$

A sífilis pode imitar várias outras entidades clinicas. ${ }^{3}$ O reconhecimento das manifestações mucosas da sífilis é fundamental para o diagnóstico e quebra da cadeia de transmissão na comunidade.

\section{REFERÊNCIAS}

1. Guerra Rodrigo F, Marques Gomes M, Mayer-da-Silva A, Filipe P. Dermatologia. Ficheiro clínico e terapêutico. $3^{a}$ ed. Lisboa: Fundação Calouste Gulbenkian; 2010.

2. Workowski KA, Berman S. Sexually transmitted diseases treatment guidelines, 2010. MMWR Recomm Rep. 2010;59:1-110.

3. Domantay-Apostol GP, Handog EB, Gabriel MT. Syphilis: the international challenge of the greta imitator. Dermatol Clin. 2008;26:191-202. 


\section{Diagnóstico de Sífilis a Partir de Lesões da Mucosa Oral \\ Acta Med Port 2014:27:403-403}

Publicado pela Acta Médica Portuguesa, a Revista Científica da Ordem dos Médicos

Av. Almirante Gago Coutinho, 151

1749-084 Lisboa, Portugal.

Tel: +351218428 215

E-mail: submissao@actamedicaportuguesa.com

www.actamedicaportuguesa.com

ISSN:0870-399X | e-ISSN: 1646-0758

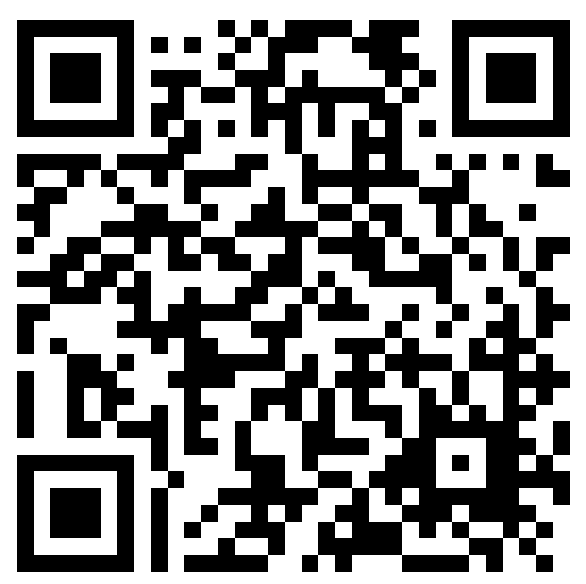

